\title{
Tiludronate concentrations and cytologic findings in synovial fluid after intravenous regional limb perfusion with tiludronate in horses
}

Barbara G Hunter, Katja Duesterdieck-Zellmer, Maureen K Larson

Anecdotal accounts of tiludronate administration via intravenous regional limb perfusion (IVRLP) exist despite a lack of information regarding safety for synovial structures in the perfused area. The objective of this study was to determine whether tiludronate concentrations in synovial structures after IVRLP with low dose $(0.5 \mathrm{mg}, \mathrm{LDT})$ or high dose (50mg, HDT) tiludronate remain below a value demonstrated in vitro to be safe for articular cartilage $(<19,000 \mathrm{ng} / \mathrm{ml})$, and to determine effects of tiludronate on synovial fluid cytology variables compared to saline perfused control limbs. Using a randomized controlled experimental study design, horses received IVRLP with LDT $(n=6)$ or HDT $(n=6)$ in one forelimb and IVRLP with saline in the contralateral limb. Synovial fluid cytology variables and tiludronate concentrations were evaluated in navicular bursae (NB), and distal interphalangeal (DIP) and metacarpophalangeal (MCP) joints one week before and 30-45 minutes after IVRLP, and in DIP and MCP joints 24 hours after IVRLP. Data were analyzed with 2-way rmANOVA $(p<0.05)$. Highest measured synovial fluid tiludronate concentrations occurred 30-45 minutes post-perfusion. Mean tiludronate concentrations were lower in LDT limbs $(\mathrm{MCP}=39.6 \pm 14.3 \mathrm{ng} / \mathrm{mL}, \mathrm{DIP}=118.1 \pm 66.6 \mathrm{ng} / \mathrm{mL}, \mathrm{NB}=82.1$ $\pm 30.2 \mathrm{ng} / \mathrm{mL}$ ) than in HDT limbs (MCP $=3,745.1 \pm 1,536.6 \mathrm{ng} / \mathrm{mL}$, DIP $=16,274.0 \pm$ $5,460.2 \mathrm{ng} / \mathrm{mL}, \mathrm{NB}=6,049.3 \pm 1,931.7 \mathrm{ng} / \mathrm{mL}$ ). Tiludronate concentration was $>19,000$ $\mathrm{ng} / \mathrm{ml}$ in DIP joints of two HDT limbs. Tiludronate was measurable only in synovial fluid from HDT limbs 24 hours post-perfusion. There were no differences in synovial fluid cytology variables between control and treated limbs. Conclusions: In some horses, IVRLP with HDT may result in synovial fluid concentrations of tiludronate that may have adverse effects on articular cartilage, based on in vitro data. IVRLP with LDT is unlikely to promote articular cartilage degradation. Further studies to determine a safe and effective dose for IVRLP with tiludronate are needed. 
Barbara G. Hunter, DVM, MS; Katja F. Duesterdieck-Zellmer, Dr.med.vet., MS, PhD, DACVS;

Maureen K. Larson, MS

Department of Clinical Sciences, College of Veterinary Medicine, Oregon State University, Corvallis, OR, USA

2 Dr. Hunter's current address is: Matamata Veterinary Services Equine, 26 Tainui Street,

3 Matamata 3400, Waikato, New Zealand

Corresponding Author: K. F. Duesterdieck-Zellmer; Department of Clinical Sciences, College of Veterinary Medicine, Oregon State University, Corvallis, OR, USA; phone: +1-541-737-8399; katja.zellmer@oregonstate.edu 


\section{Introduction}

Tiludronate is a non-nitrogenous bisphosphonate used in humans for the treatment of Paget's

7 disease and osteoporosis, because it normalizes bone-turnover at therapeutic doses (Bonjour et al.,

8 1995). In recent years, tiludronate has been utilized in horses for treatment of diseases related to

9 abnormal bone remodeling (Kamm, Mcllwraith \& Kawcak, 2008) and has reportedly been effective in

10 some horses in reducing pain associated with navicular disease (Denoix, Thibaud \& Riccio, 2003),

11 distal hock osteoarthritis (Gough, Thibaud \& Smith, 2010) and thoracolumbar osteoarthritis (Coudry et

12 al., 2007). Complications associated with systemic administration of tiludronate include mild

13 tachycardia during administration and transient hypocalcemia following injection (Varela et al., 2002).

14 Anecdotally, signs of colic and acute renal failure have also been encountered. Presumably to decrease

15 the occurrence of complications associated with systemic administration of tiludronate, and to decrease

16 the cost of treatment, equine practitioners are currently administering tiludronate via intravenous

17 regional limb perfusion (IVRLP) for the treatment of navicular disease and other orthopaedic

18 conditions of the distal limb (Carpenter, 2012). Doses that are anecdotally being used for IVRLP

19 however, such as $50 \mathrm{mg}$ per perfusion, are lacking evaluation of safety for tissues within the perfused

20 region.

21 Although the target organ for bisphosphonates is bone, tiludronate also has effects on articular

22 cartilage that are concentration dependent. Concentrations of $\geq 19,000 \mathrm{ng} / \mathrm{ml}$ enhanced chondrocyte

23 apoptosis and proteoglycan release in equine articular cartilage explants (Duesterdieck-Zellmer,

24 Driscoll \& Ott, 2012). Administration of medications such as antibiotics via intravenous regional limb

25 perfusion allows veterinarians to attain considerably higher tissue and synovial fluid concentrations

26 than can be achieved with systemic administration (Rubio-Martinez \& Cruz, 2006). Assuming that

27 IVRLP with tiludronate follows similar pharmacokinetics, cartilage within the perfused area may

28 potentially be exposed to synovial fluid tiludronate concentrations that promote cartilage degradation. 
29 Therefore the objectives of the current study were to determine tiludronate concentrations achieved in

30 distal limb synovial structures following intravenous regional limb perfusion with a low (0.5 mg; LDT)

31 or high (50 mg; HDT) dose of tiludronate and to determine the effects of these two dosing regimens on

32 synovial fluid cytology variables compared to placebo controlled limbs. The working hypothesis was

33 that IVRLP with LDT would result in synovial fluid concentrations that were safe for cartilage in vitro

$34(<19,000 \mathrm{ng} / \mathrm{ml}$; Duesterdieck-Zellmer, Driscoll \& Ott, 2012) and that synovial fluid cytology variables

35 would not vary significantly from controls. It was further hypothesized that IVRLP with $50 \mathrm{mg}$ of

36 tiludronate (HDT), the lowest of three doses currently used in clinical practice to the knowledge of

37 these authors, would result in synovial fluid concentrations that are unsafe for cartilage in vitro

$38(\geq 19,000 \mathrm{ng} / \mathrm{ml}$; Duesterdieck-Zellmer, Driscoll \& Ott, 2012) and that synovial fluid cytology variables

39 in treated limbs would differ from control limbs.

\section{Materials and Methods}

42 Animals

43 All experimental procedures were performed with the approval of the Institutional Animal Care 44 and Use Committee of Oregon State University (ACUP\# 4280 and 4459). Six adult healthy horses

45 (mean body weight, $600 \mathrm{~kg}$; range, 514-636 kg; mean age, 10.6 years; range 4-17 years; breed, 1

46 Thoroughbred, 3 Quarter Horses, 1 Warmblood, 1 Quarter Horse cross) were used for the LDT trial

47 and one year later, six different healthy horses (mean weight, $480 \mathrm{~kg}$, range, $414-545 \mathrm{~kg}$; mean age,

4812.5 years; range, 12-19 years; breed, 1 Rocky Mountain Horse, 1 Appaloosa, 1 Morgan, 1 Quarter

49 Horse, 1 American Paint Horse and 1 Arabian cross) were used for the HDT trial. All horses were

50 graded for lameness from 0 to 5 according to guidelines by the American Association of Equine

51 Practitioners (Stashak, 2002). Further, response to lower front limb flexion tests was recorded. All

52 horses were sound at a walk, but most showed mild front limb lameness at the trot. Horses were housed 
53 in box stalls or small paddocks, given free access to grass hay and water and underwent daily physical

54 exams for the duration of the experiments. None of the horses had ever received tiludronate prior to

55 these experiments. Systematic assessment of initial comparability between treated and control limbs

56 with respect to lameness or synovial cytologic response variables was not performed.

57 Experimental Protocol

58 After initial examination, horses were sedated with detomidine (Dormosedan, Pfizer Animal

59 Health, New York, NY, USA; 0.01-0.015 mg/kg IV) and were given additional doses of detomidine

60 and/or butorphanol (Torbugesic, Zoetis Animal Health, Florham Park, NJ, USA; $0.01 \mathrm{mg} / \mathrm{kg}$ ) as

61 needed. Distal forelimbs were locally anesthetized using high four-point perineural blocks with

62 bupivacaine (Marcaine, Hospira Inc, Lake Forest, IL, USA) to facilitate sample collection and IVRLP.

63 Baseline synovial fluid samples were collected aseptically from both distal interphalangeal and

64 metacarpophalangeal joints and from the navicular bursae under radiographic guidance (Boyce et al.,

65 2010). Distal limbs were bandaged for 24 hours following synoviocenteses.

Seven days later, horses were sedated and distal forelimbs were locally anesthetized as

67 described above. IVRLP was performed aseptically by an investigator who was blinded to treatment

68 allocations $(\mathrm{BH})$ on one randomly assigned front limb either with $0.5 \mathrm{mg}$ tiludronate (Tildren, CEVA,

69 Libourne, France; $\mathrm{n}=6$; LDT) or with $50 \mathrm{mg}$ tiludronate ( $\mathrm{n}=6$; HDT), both diluted in $50 \mathrm{ml}$ saline. The

70 contralateral forelimb received IVRLP with $50 \mathrm{ml}$ saline alone to serve as a placebo control. Briefly,

71 rolled gauze pads were placed on either side of the flexor tendons in the proximal half of the

72 metacarpus, followed by application of a 10.2-cm wide rubber tourniquet (Esmark Bandage, Cardinal

73 Health, McGraw Park, IL, USA) to cover 15-18 cm of the metacarpus. Tourniquets were applied as

74 tightly as possible by the same investigator $(\mathrm{BH})$ each time. A 21 -gauge 1.9-cm butterfly catheter

75 (Surflo Winged Infusion Set, Terumo Corporation, Tokyo, Japan) was inserted into a palmar digital

76 vein and the perfusate was injected over 3-5 minutes. Catheters were removed immediately following 
77 infusions and a temporary bandage of gauze and elastic wrap (Coflex, Andover, Salisbury, MA, USA)

78 was applied over the venipuncture site. Bandages and tourniquets were left in place for 30 minutes.

Just prior to tourniquet removal, $10 \mathrm{ml}$ of venous blood was obtained from the jugular vein for analysis of serum tiludronate concentrations. Immediately following tourniquet removal, synovial fluid

81 samples were obtained from distal interphalangeal and metacarpophalangeal joints, as well as the

82 navicular bursae as described above. Synoviocentesis of distal interphalangeal and

83 metacarpophalangeal joints was performed simultaneously by 2 investigators (BGH and FKDZ) at 30-

8435 minutes and synoviocentesis of the navicular bursa was performed at 35-45 minutes after injection

85 of the perfusate.Distal limbs were subsequently bandaged.

Twenty-four hours following IVRLP, horses were evaluated for lameness as described above

by an investigator blinded to treatment allocation (BGH). Horses treated with LDT were sedated again and synovial fluid was collected as described from both distal interphalangeal and metacarpophalangeal joints. Subsequently, daily lameness examinations were performed for an additional seven days before being released from the study. In horses treated with HDT, synovial fluid

91 was collected from the same joints, after euthanasia via intravenous injection of pentobarbital

92 (Beuthanasia-D Special, Schering Plough Animal Health, Kenilworth, NJ, USA; 87 mg/kg IV).

93 Sample Processing and Analysis

94 All sample processing and analyses were performed by personnel blinded to treatment

95 allocation. Following sample collection, $200-300 \mu \mathrm{L}$ of synovial fluid was placed in a $2 \mathrm{ml}$ vial

96 containing 7.5\% EDTA liquid (Monoject, Tyco Healthcare, Mansfield, MA, USA) for cytology

97 analysis. Total solids were measured using a refractometer (E-line Veterinary, Bellingham+Stanley,

98 Basingstoke, Hampshire, UK). Total nucleated cell counts were determined manually (BMP Leuko-

99 Tik, BMP Biomedical Polymers, Gardner, MA, USA). Differential cell counts were performed on 
100 Wright Giemsa stained cytospin slides (CytoSpin* 4 Cytocentrifuge, Thermo Scientific, Waltham, 101 MA, USA).

102 Jugular blood samples were allowed to clot at room temperature for 30 minutes and centrifuged 103 at $3500 \mathrm{xg}$ for 5 minutes. Serum was separated and frozen at $-80^{\circ} \mathrm{C}$ until tiludronate analysis. Synovial

104 fluid was centrifuged at $10,000 \times \mathrm{x}$ for 30 minutes at $4{ }^{\circ} \mathrm{C}$, the supernatant was aspirated and frozen at $10580^{\circ} \mathrm{C}$ until tiludronate analysis.

106 Tiludronate analysis was performed as previously described (Duesterdieck-Zellmer et al., 2014) 107 using high performance liquid chromatography (XBridge phenyl column, Waters, Milford, MA, USA)

108 followed by mass spectrometry (API 4000, Applied Biosystems, Grand Island, NY, USA) . Briefly,

109 tiludronate in all samples was methylated with $0.2 \mathrm{M}$ trimethylsilyldiazomethane in acetone.

110 Concentrations of methylated tiludronate were determined against known standard samples $(10-64$

$111 \mathrm{ng} / \mathrm{ml}$ ). An additional standard sample with a tiludronate concentration of $0.5 \mathrm{ng} / \mathrm{ml}$ was used to

112 determine presence or absence of tiludronate below the linear part of the standard curve. For synovial

113 fluid samples, tiludronate standards were procured in equine synovial fluid and for serum samples

114 standards were generated in equine serum from untreated horses euthanized for reasons unrelated to

115 this study. The same standards were used for low dose trial samples as for high dose trial samples.

116 Serial dilutions were performed on all samples with tiludronate concentrations above the range of the

117 standard curve. All unknown and standard curve samples were spiked with a known amount of

118 deuterated tiludronate (Toronto Research Chemicals, Toronto, Ontario, Canada) as an internal control.

119 Further, positive and negative control samples were run concurrently with each batch of samples. The

120 lower limit of accurate quantification of the assay was $10 \mathrm{ng} / \mathrm{ml}$.

\section{Data Analysis}

122 Results for cytology variables and lameness grades are reported as mean \pm standard error and

123 for tiludronate concentrations as mean [lowest-highest measurement]. Normal distribution of data was 
124 assured using the Anderson-Darling normality test. Cytology variables for each joint and lameness

125 grades for each limb were compared to baseline values over time and between treated and control

126 limbs for the low dose trial and the high dose trial separately using two-way repeated measures

127 ANOVA followed by Holm-Sidak's multiple comparisons tests. Statistical significance was set at $\mathrm{P} \leq$ 1280.05 and analyses were performed in Graphpad Prism (Graph Pad Software, San Diego, CA, USA).

130 Results

All horses were sound at a walk prior to treatment and remained sound at a walk after treatment. Mean lameness grade seven days prior to treatment was $0.8 \pm 1.0$ and $0 \pm 0$ for LDT and 133 control limbs, respectively and $0.5 \pm 0.3$ for HDT and control limbs, respectively. No differences over 134 time or between treated and control limbs were found in horses treated with LDT. Limbs treated with 135 HDT had significantly higher lameness scores the day after IVRLP $(2.0 \pm 0.5)$ compared to seven days 136 prior to IVRLP ( $\mathrm{p}=0.0048)$ and this was not the case for the control limbs. Further, limbs treated with 137 HDT had significantly higher lameness scores than control limbs $(0.3 \pm 0.3)$ on the day after IVRLP 138 ( $\mathrm{p}=0.0036$ ). In one horse with a limb that was positive to distal limb flexion prior to IVRLP with LDT, 139 the positive response to distal limb flexion was unchanged after IVRLP. No other horses displayed 140 positive distal limb flexion tests before or after IVRLP.

141 Synovial fluid total solids concentration (Figure 1) was not significantly different in any

142 synovial structure between LDT and control limbs, or between HDT and control limbs, and there was 143 no difference over time in total solids concentration in any synovial structure of treated or control 144 limbs.

145 Total nucleated cell count in synovial fluid (Figure 2) was not significantly different in any 146 synovial structure between LDT and control limbs, or between HDT and control limbs. However, 24 147 hours after IVRLP, total nucleated cell count was increased in the metacarpophalangeal joints of limbs 
148 treated with LDT, HDT, and saline. In the distal interphalangeal joint, total nucleated cell count was

149 increased in saline treated limbs of the HDT group.

150 Synovial fluid neutrophil count (Table 1) was not significantly different in any synovial

151 structure between LDT and control limbs, or between HDT and control limbs, and there was no

152 difference over time in neutrophil count in any of the synovial structures of treated or control limbs.

153 Tiludronate concentrations in synovial fluid are reported in Table 2. Tiludronate was not

154 detected in any samples prior to IVRLP. In horses receiving LDT, tiludronate was detectable in

155 synovial fluid of saline perfused limbs immediately after tourniquet release, albeit at concentrations

156 below the lower limit of accurate quantification of the assay. Tiludronate concentration was detected at

157 higher concentrations in synovial fluid of the LDT limbs immediately after tourniquet release, but was

158 no longer detectable by 24 hours post-perfusion. Highest tiludronate concentrations were measured in

159 synovial fluid samples from HDT limbs immediately after tourniquet release, and tiludronate was still

160 present in samples taken 24 hours after IVRLP. In control limbs of HDT horses, tiludronate was

161 present in synovial fluid immediately after tourniquet release. However, 24 hours after IVRLP,

162 tiludronate was detected only below the lower limit of accurate quantification of the assay in saline

163 treated limbs of horses receiving HDT.

164 In HDT horses, tiludronate concentration in serum immediately prior to tourniquet release was

$165111.5 \mathrm{ng} / \mathrm{ml}[0.0-300.0]$ and in LDT horses, serum tiludronate concentration was below the lower limit

166 of accurate quantification of the assay.

168 Discussion and Conclusions

169 Before IVRLP with tiludronate should be investigated further as a possible therapy for distal

170 limb orthopedic disease in horses, it should first be determined whether tiludronate concentrations

171 achieved in the perfused area are safe for the perfused tissues. This study determined synovial fluid 
172 concentrations of tiludronate after IVRLP with 0.5 or $50 \mathrm{mg}$ tiludronate diluted in $50 \mathrm{ml}$ saline as a

173 first step in assessing the safety of this technique for articular cartilage in the perfused area. A

174 previously published in vitro concentration-response study suggested that synovial fluid tiludronate

175 concentrations of $\geq 19,000 \mathrm{ng} / \mathrm{ml}$ may be unsafe for healthy articular cartilage and concentrations of

$176 \geq 1,900,000 \mathrm{ng} / \mathrm{ml}$ may be unsafe for osteoarthritic cartilage (Duesterdieck-Zellmer, Driscoll \& Ott,

177 2012). While mean synovial fluid tiludronate concentrations in the present study did not exceed 19,000

$178 \mathrm{ng} / \mathrm{ml}$, recorded concentrations varied greatly between individual horses and synovial structures.

179 Synovial fluid tiludronate concentration was $>30,000 \mathrm{ng} / \mathrm{ml}$ upon tourniquet release in the distal

180 interphalangeal joint of two limbs treated with HDT. This is concerning since concentrations of this

181 magnitude increased chondrocyte apoptosis and proteoglycan release from articular cartilage matrix in

182 vitro (Duesterdieck-Zellmer, Driscoll \& Ott, 2012). However, these findings have not yet been

183 confirmed in vivo. Synovial fluid tiludronate concentrations $>2,000,000 \mathrm{ng} / \mathrm{ml}$ after intraarticular

184 administration of $50 \mathrm{mg}$ tiludronate into equine middle carpal joints were not associated with worse

185 cartilage histology scores or decreased proteoglycan content at two weeks after treatment when

186 compared to saline treated joints in four horses (Duesterdieck-Zellmer et al., 2014). Nevertheless,

187 tiludronate treated joints showed temporarily increased proteoglycan degradation and amelioration of

188 increases in aggrecan synthesis compared to control joints, as determined by synovial fluid biomarkers.

189 Although the clinical significance of these findings was uncertain, it is possible that IVRLP with $50 \mathrm{mg}$

190 of tiludronate diluted to $50 \mathrm{ml}$ with saline may not be safe for articular cartilage in the distal

191 interphalangeal joints of some horses.

192 Great variability in synovial fluid drug concentrations after IVRLP has been previously

193 reported (Santschi \& Papich, 1999; Butt et al., 2001; Murphey, Parra-Sanchez et al., 2006; Levine et

194 al., 2010; Hyde et al., 2013; Mahne et al., 2014) and has been attributed to leakage of perfusate from

195 the distal limb across the tourniquet, which occurred to a small extent in all horses of this study, and 
196 variable drug doses on a per bodyweight basis (Butt et al., 2001). Perivascular injection of perfusate

197 could also contribute to variability in synovial fluid tiludronate concentrations, but in the present study,

198 injection of perfusate was interrupted at the first sign of this occurring. Subsequently, the coaxial

199 palmar digital vein of the same limb was used to complete the injection, while an assistant was holding

200 off the initial venipuncture site. Interestingly, horses with the lowest serum concentrations of

201 tiludronate prior to tourniquet release were not consistently found to have the highest synovial fluid

202 tiludronate concentrations in treated limbs, suggesting that serum drug concentration is only a marginal

203 indicator of synovial fluid tiludronate concentration after IVRLP.

204 Highest tiludronate concentrations were measured in synovial fluid from distal interphalangeal

205 joints, followed by the navicular bursa and finally the metacarpophalangeal joints of HDT and LDT

206 limbs. A similar pattern has been described for synovial fluid concentrations of antibiotics after IVRLP

207 (Butt et al., 2001; Rubio-Martinez et al., 2006). Possible explanations for this phenomenon include the

208 injection of perfusate at the level of the metacarpophalangeal joint in a distad direction, favoring

209 perfusion of more distally located synovial structures, as well as differences in ratio of synovial fluid

210 volume to synovial lining surface (Rubio-Martinez et al., 2006).

211 As expected, synovial fluid tiludronate concentrations increased in a dose dependent fashion in

212 the present study. Highest concentrations were found immediately following tourniquet removal and

213 negligible concentrations were documented in synovial fluid 24 hours after IVRLP. In a relevant

214 report, radioactively labeled bisphosphonate (technetium Tc $99 \mathrm{~m}$ medronate) followed a similar pattern

215 after intraarticular administration into equine antebrachiocarpal joints, and elimination of the

216 bisphosphonate from the joint space was suggested to occur via transfer from synovial fluid to plasma

217 (Dulin et al., 2012). Although this has not been assessed, it is conceivable that bisphosphonates may

218 also diffuse into articular cartilage and subchondral bone, following their affinity for calcium.

219 Detection of tiludronate at low concentrations in control joints as was documented in the present study 
220 has also been reported after intraarticular injection of tiludronate in horses (Duesterdieck-Zellmer et al.,

221 2014), and likely reflected a mild degree of tourniquet escape during IVRLP, as well as redistribution

222 from perfused tissues into systemic circulation after tourniquet release. In comparison, serum

223 concentrations prior to tourniquet release in this study were about 10 and 100 times lower than

224 maximum plasma concentrations after systemic intravenous administration of $0.1 \mathrm{mg} / \mathrm{kg}$ and $10 \mathrm{mg} / \mathrm{kg}$

225 tiludronate in horses, respectively (Delguste et al. 2008). This study also determined that IVRLP with high or low dose tiludronate did not significantly

227 change synovial fluid cytology variables in comparison to saline control. Changes in synovial fluid 228 cytology variables over time, specifically elevation of total nucleated cell counts 24 hours after IVRLP, 229 were observed in all limbs, regardless of specific treatment. These alterations may be due to repeated

230 synoviocenteses or the process of IVRLP itself. Repeated synoviocentesis every 12 (White et al., 1989)

231 or 48 hours (Sanchez Teran et al., 2012) has been shown to significantly increase total nucleated cell

232 counts in comparison to baseline. The elevation in total nucleated cell counts could also be due to

233 diffusion of saline into the synovial cavity following IVRLP. Intraarticular injection of saline has been

234 shown to cause acute synovial inflammation with significant increases in synovial fluid white blood

235 cell counts and total protein concentration 24 hours after injection (Wagner, Mcllwraith \& Martin, 236 1982).

237 Isotonic saline was chosen as the diluent in this study, as tiludronate may bind calcium if 238 diluted with polyionic, physiologic solutions. A dilution volume of $50 \mathrm{ml}$ was chosen as this is a 239 commonly reported infusion volume for IVRLP with antibiotics (Levine et al., 2010; Kelmer et al., 240 2013a; Kelmer et al., 2013b). However, a recent study suggested that lower perfusate volumes tend to

241 result in higher synovial fluid concentrations of antibiotics within the perfused area (Hyde et al., 2013).

242 Thus, the tiludronate concentrations achieved in this study may not represent what would be achieved

243 if a lower perfusate volume was used. 
A limitation of this study was the use of horses that had variable degrees of lameness at a trot

245 prior to any experimental manipulations. Attempts to compensate for this weakness were made by

246 evaluating horses for changes in lameness from baseline. Statistical analysis suggested an increase in

247 lameness score in HDT but not saline control limbs 24 hours after treatment when compared to

248 baseline lameness scores and significantly greater lameness in HDT limbs than control limbs at the

249 same time point. However, randomization of treatments resulted in none of the lame limbs being

250 assigned to control treatments and all lame limbs being assigned to tiludronate treatments. Thus, we are

251 unable to determine whether or not IVRLP with tiludronate results in clinically appreciable lameness

252 based on our experiments and further investigation of this aspect is warranted. Nevertheless, results

253 pertaining to synovial fluid tiludronate concentrations and cytology variables are still valid, as

254 lameness by itself is unlikely to influence these variables in non-exercised horses.

255 Since the therapeutic target tissue of tiludronate is bone, future studies evaluating safety of

256 IVRLP with different doses of tiludronate for bone are essential before determination of possible

257 therapeutic efficacy is undertaken. While the target cells of tiludronate are osteoclasts, there is some

258 evidence that high concentrations of bisphosphonates can induce apoptosis also in osteoblasts

259 (Patntirapong et al., 2012), emphasizing the need to ascertain that bone concentrations of tiludronate

260 after IVRLP are not high enough to negatively impact cells in bone other than osteoclasts.

261 This study represents a first step to determine the safety of IVRLP with tiludronate for articular

262 cartilage within the perfused area. Findings suggest that IVRLP with either $0.5 \mathrm{mg}$ or $50 \mathrm{mg}$ of

263 tiludronate did not cause synovial inflammation in comparison to saline controls. Further, synovial

264 fluid concentrations of tiludronate after IVRLP with $0.5 \mathrm{mg}$ tiludronate were within a range that can be

265 considered safe for cartilage based on previous in vitro data (Duesterdieck-Zellmer, Driscoll \& Ott,

266 2012). However, after IVRLP with $50 \mathrm{mg}$ tiludronate, some horses may experience synovial fluid

267 concentrations that may not be safe for articular cartilage of the distal interphalangeal joint. 


\section{Acknowledgments}

We would like to thank Lauren Hobstetter for her assistance with the experiments.

\section{References}

273 Bonjour JP, Ammann P, Barbier A, Caverzasio J, Rizzoli R. 1995. Tiludronate: bone pharmacology and safety. Bone 17:473S-477S.

275 Boyce M, Malone ED, Anderson LB, Park S, Godden SM, Jenner F, Trumble TN. 2010. Evaluation of diffusion of triamcinolone acetonide from the distal interphalangeal joint into the navicular bursa in horses. American Journal of Veterinary Research 71:169-175.

Butt TD, Bailey JV, Dowling PM, Fretz PB. 2001. Comparison of 2 techniques for regional antibiotic delivery to the equine forelimb: intraosseous perfusion vs. intravenous perfusion. Canadian Veterinary Journal 42:617-622.

281 Carpenter RS. 2012. How to treat dorsal metacarpal disease with regional tiludronate and extracorporeal shock wave therapies in Thoroughbred racehorses. Proceedings of the Annual Convention of the American Association of Equine Practitioners. Anaheim, CA: AAEP. p 546549.

Coudry V, Thibaud D, Riccio B, Audigie F, Didierlaurent D, Denoix JM. 2007. Efficacy of tiludronate in the treatment of horses with signs of pain associated with osteoarthritic lesions of the thoracolumbar vertebral column. American Journal of Veterinary Research 68:329-337.

Davidson EJ, Orsini JA. 2007. Arthrocentesis and synovial fluid analysis. In: Orsini JA, Divers TJ, eds. Equine emergencies: treatment and procedures. 3rd edition. St. Louis, MO: Saunders Elsevier, $272-273$. 
291 Delguste C, Amory H, Guyonnet J, Thibaud D, Garnero P, Detilleux J, Lepage OM, Doucet M. 2008. 292 Comparative pharmacokinetics of two intravenous administration regimes of tiludronate in 293 healthy adult horses and effect on the bone resorption marker CTX-1. J Vet Pharmacol Ther $294 \quad 31: 108-116$.

295 Denoix JM, Thibaud D, Riccio B. 2003. Tiludronate as a new therapeutic agent in the treatment of 296 navicular disease: a double-blind placebo-controlled clinical trial. Equine Veterinary Journal 35:407-413. equine articular cartilage explants incubated with and without interleukin-1beta. American

Duesterdieck-Zellmer KF, Driscoll N, Ott JF. 2012. Concentration-dependent effects of tiludronate on Journal of Veterinary Research 73:1530-1539.

Duesterdieck-Zellmer KF, Moneta L, Ott JF, Larson MK, Gorman EM, Hunter B, Lohr CV, Payton ME, Morre JT, Maier CS. 2014. Effects of low and high dose intraarticular tiludronate on synovial fluid and clinical variables in healthy horses-a preliminary investigation. PeerJ 2:e534.

Dulin JA, Drost WT, Phelps MA, Santschi EM, Menendez MI, Bertone AL. 2012. Influence of exercise on the distribution of technetium Tc $99 \mathrm{~m}$ medronate following intra-articular injection in horses. American Journal of Veterinary Research 73:418-425.

Gough MR, Thibaud D, Smith RK. 2010. Tiludronate infusion in the treatment of bone spavin: a double blind placebo-controlled trial. Equine Veterinary Journal 42:381-387.

Hyde RM, Lynch TM, Clark CK, Slone DE, Hughes FE. 2013. The influence of perfusate volume on antimicrobial concentration in synovial fluid following intravenous regional limb perfusion in the standing horse. Canadian Veterinary Journal 54:363-367.

312 Kamm L, Mcllwraith W, Kawcak C. 2008. A review of the efficacy of tiludronate in the horse. Journal of Equine Veterinary Science 28:209-214. 
314 Kelmer G, Bell GC, Martin-Jimenez T, Saxton AM, Catasus C, Elliot SB, Meibohm B. 2013a. Evaluation of regional limb perfusion with amikacin using the saphenous, cephalic, and palmar digital veins in standing horses. Journal of Veterinary Pharmacology and Therapeutics 36:236240.

Kelmer G, Martin-Jimenez T, Saxton AM, Catasus C, Elliot SB, Lakritz J. 2013b. Evaluation of regional limb perfusion with erythromycin using the saphenous, cephalic, or palmar digital veins in standing horses. Journal of Veterinary Pharmacology and Therapeutics 36:434-440.

Levine DG, Epstein KL, Ahern BJ, Richardson DW. 2010. Efficacy of three tourniquet types for intravenous antimicrobial regional limb perfusion in standing horses. Veterinary Surgery 39:1021-1024.

Mahaffey EA. 2002. Synovial fluid. In: Cowell RL, Tyler RD, eds. Diagnostic cytology and hematology of the horse. 2nd edition. St. Louis, MO: Mosby, 163-170.

Mahne AT, Rioja E, Marais HJ, Villarino NF, Rubio-Martinez LM. 2014. Clinical and pharmacokinetic effects of regional or general anaesthesia on intravenous regional limb perfusion with amikacin in horses. Equine Veterinary Journal 46:375-379.

Murphey ED, Santschi EM, Papich MG. 1999. Regional intravenous perfusion of the distal limb of horses with amikacin sulfate. Journal of Veterinary Pharmacology and Therapeutics 22:68-71.

Parra-Sanchez A, Lugo J, Boothe DM, Gaughan EM, Hanson RR, Duran S, Belknap JK. 2006. Pharmacokinetics and pharmacodynamics of enrofloxacin and a low dose of amikacin administered via regional intravenous limb perfusion in standing horses. American Journal of Veterinary Research 67:1687-1695.

Patntirapong S, Singhatanadgit W, Chanruangvanit C, Lavanrattanakul K, Satravaha Y. 2012. Zoledronic acid suppresses mineralization through direct cytotoxicity and osteoblast differentiation inhibition. Journal of Oral Pathology and Medicine 41:713-720. 
338 Rubio-Martinez LM, Cruz AM. 2006. Antimicrobial regional limb perfusion in horses. Journal of the American Veterinary Medical Association 228:706-712, 655.

340 Rubio-Martinez LM, Lopez-Sanroman J, Cruz AM, Tendillo F, Rioja E, San Roman F. 2006.

341 Evaluation of safety and pharmacokinetics of vancomycin after intraosseous regional limb

342 perfusion and comparison of results with those obtained after intravenous regional limb

343 perfusion in horses. American Journal of Veterinary Research 67:1701-1707.

344 Sanchez Teran AF, Rubio-Martinez LM, Villarino NF, Sanz MG. 2012. Effects of repeated intra-

345 articular administration of amikacin on serum amyloid A, total protein and nucleated cell count

346 in synovial fluid from healthy horses. Equine Veterinary Journal Supplement:12-16.

347 Stashak TS. 2002. Examination for lameness. In: Stashak TS, ed. Adams Lameness in Horses. 5 ed.

$348 \quad$ Philadelphia, PA: Lippincott Williams \& Wilkins, 113-175.

349 Varela AM, Lepage OM, Doucet M, Marcoux M, Garnero P. 2002. Tiludronate chez le cheval:

350 Tolerance et effets a court terme sur le metabolisme osseux. Annales de médecine vétérinaire

$351 \quad 147: 123-130$.

352 Wagner AE, McIlwraith CW, Martin GS. 1982. Effect of intra-articular injection of orgotein and saline 353 solution on equine synovia. American Journal of Veterinary Research 43:594-597.

354 White KK, Hodgson DR, Hancock D, Parry BW, Cordell C. 1989. Changes in equine carpal joint 355 synovial fluid in response to the injection of two local anesthetic agents. Cornell Veterinarian $356 \quad 79: 25-38$. 


\section{Table 1 (on next page)}

table of percentage of neutrophils in synovial fluid

Table 1: Mean percentage and standard error of the mean of neutrophils among all nucleated cells in synovial fluid over time after IVRLP with $0.5 \mathrm{mg}$ (LDT) or $50 \mathrm{mg}$ (HDT) tiludronate diluted in $50 \mathrm{ml}$ saline in one randomly assigned forelimb or with $50 \mathrm{ml}$ saline in the contralateral forelimb as control for the low dose (LDC) or as control for the high dose of tiludronate (HDC). Mahaffey (2002) suggests that the proportion of neutrophils in normal synovial fluid should not exceed $10 \%$, except in samples with very low cell counts. 
Metacarpophalangeal joint

\begin{tabular}{|c|rr|rr|rr|}
\hline & \multicolumn{2}{|c|}{ baseline } & \multicolumn{2}{|c|}{$30-35 \mathrm{~min}$} & \multicolumn{2}{|c|}{$24 \mathrm{~h}$} \\
\hline LDC & 2.3 & {$[1.1]$} & 3.3 & {$[2.0]$} & 16.8 & {$[5.9]$} \\
\hline LDT & 9.2 & {$[9.0]$} & 6.5 & {$[4.2]$} & 22.8 & {$[6.2]$} \\
\hline HDC & 5.3 & {$[1.8]$} & 5.3 & {$[1.8]$} & 5.3 & {$[1.8]$} \\
\hline HDT & 5.8 & {$[3.6]$} & 0.7 & {$[0.4]$} & 5.8 & {$[2.1]$} \\
\hline
\end{tabular}

Distal interphalangeal joint

\begin{tabular}{|c|rl|rl|rl|}
\hline & \multicolumn{2}{|c|}{ baseline } & \multicolumn{2}{|c|}{$30-35 \mathrm{~min}$} & \multicolumn{2}{|c|}{$24 \mathrm{~h}$} \\
\hline LDC & 18.7 & {$[6.9]$} & 6.5 & {$[1.9]$} & 10.8 & {$[4.9]$} \\
\hline LDT & 22.0 & {$[10.1]$} & 22.3 & {$[7.6]$} & 8.8 & {$[2.5]$} \\
\hline HDC & 1.3 & {$[0.9]$} & 10.5 & {$[5.1]$} & 13.0 & {$[3.1]$} \\
\hline HDT & 5.5 & {$[3.2]$} & 16.2 & {$[9.7]$} & 6.8 & {$[2.1]$} \\
\hline
\end{tabular}

Navicular bursa

\begin{tabular}{|c|rl|rl|}
\hline & \multicolumn{2}{|c|}{ baseline } & \multicolumn{2}{|c|}{$35-45 \mathrm{~min}$} \\
\hline LDC & 8.7 & {$[3.8]$} & 13.7 & {$[8.0]$} \\
\hline LDT & 11.3 & {$[4.3]$} & 8.1 & {$[5.4]$} \\
\hline HDC & 16.6 & {$[10.3]$} & 25.8 & {$[14.6]$} \\
\hline HDT & 9.0 & {$[7.2]$} & 13.2 & {$[8.0]$} \\
\hline
\end{tabular}




\section{Table 2 (on next page)}

Table of synovial fluid tiludronate concentrations

Table 2: Mean [lowest-highest measurement] tiludronate concentrations in $\mathrm{ng} / \mathrm{ml}$ in synovial fluid before and after IVRLP with tiludronate or saline. An asterisk indicates that tiludronate was detectable in synovial fluid, albeit below the level of quantitation for the assay (10 $\mathrm{ng} / \mathrm{ml})$. 


\begin{tabular}{|c|c|c|c|c|}
\hline & \multicolumn{4}{|c|}{ Metacarpophalangeal joint } \\
\hline & baseline & $30-35$ & & $24 \mathrm{~h}$ \\
\hline LDC & 0.0 & $0.0 *$ & & 0.0 \\
\hline LDT & 0.0 & 39.6 & {$[0.0-101.8]$} & 0.0 \\
\hline $\mathrm{HDC}$ & 0.0 & 24.6 & {$[0.0-67.3]$} & $0.0^{*}$ \\
\hline HDT & 0.0 & 3,745 . & {$[763.2-10,850.0]$} & 70.8 \\
\hline
\end{tabular}

\begin{tabular}{|l|l|ll|ll|}
\hline \multicolumn{5}{|l|}{ Distal interphalangeal joint } \\
\hline & baseline & $30-35$ min & $24 \mathrm{~h}$ & \\
\hline LDC & 0.0 & $0.0 *$ & {$[26.6-449.6]$} & 0.0 & \\
\hline LDT & 0.0 & 118.1 & {$[38.9-155.6]$} & $0.0 *$ & \\
\hline HDC & 0.0 & 76.6 & {$[4,390.0-33,700.0]$} & 16.5 & {$[0.0-30.6]$} \\
\hline HDT & 0.0 & $16,274.0$ & & & \\
\hline
\end{tabular}

\begin{tabular}{|l|l|ll|}
\hline & \multicolumn{3}{|l|}{ Navicular bursa } \\
\hline & baseline & $35-45$ min & \\
\hline LDC & 0.0 & $0.0 *$ & \\
\hline LDT & 0.0 & 82.1 & {$[0.0-195.8]$} \\
\hline HDC & 0.0 & 89.0 & {$[12.6-182]$} \\
\hline HDT & 0.0 & $6,049.3$ & {$[211.0-11,187.0]$} \\
\hline
\end{tabular}


1

Bar graphs illustrating synovial fluid total solids concentrations after IVRLP with tiludronate or saline 
A metacarpophalangeal joint

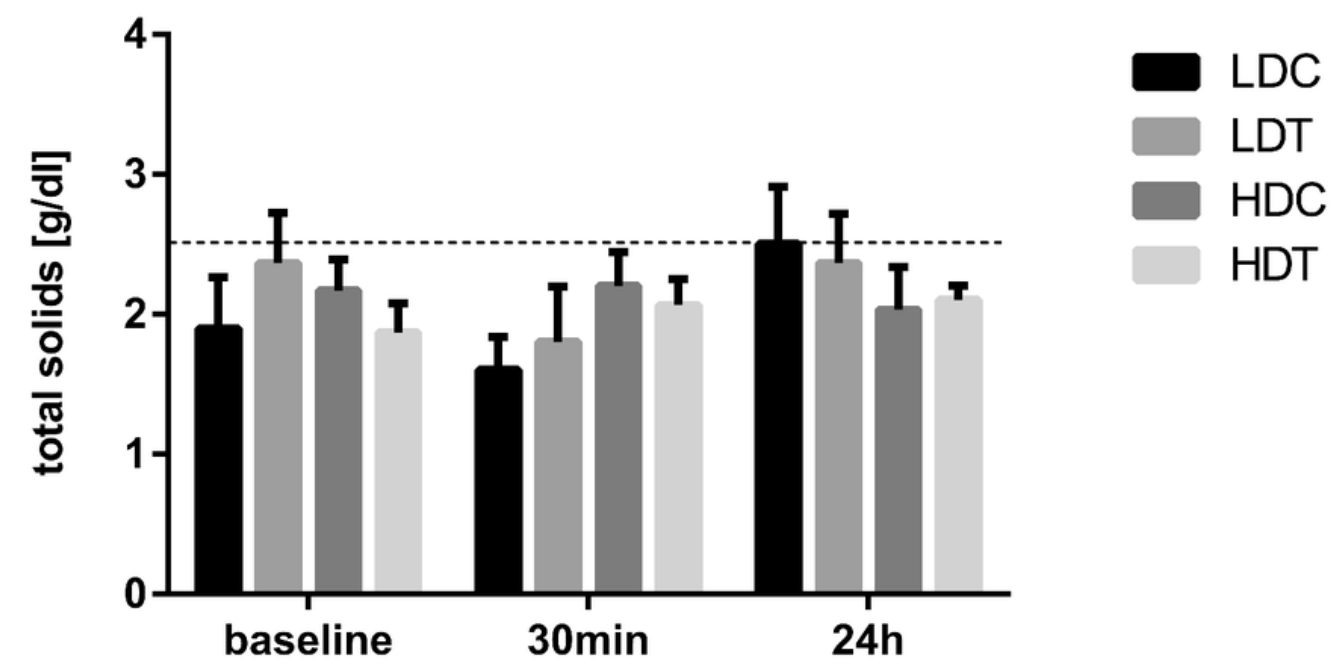

B

coffin joint

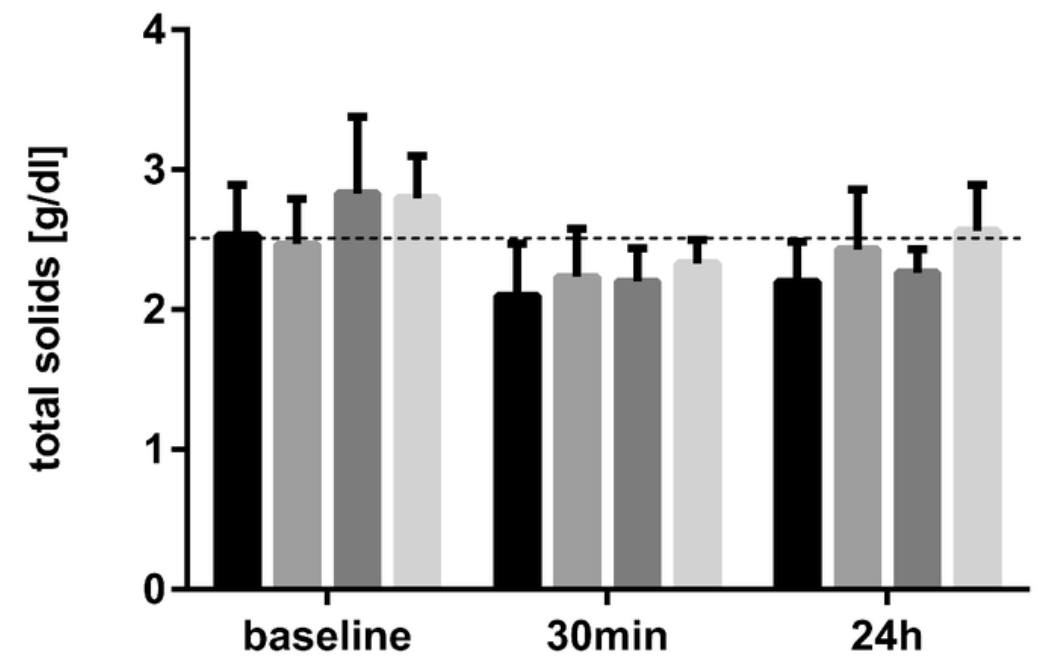

- LDC

LDT

HDC

HDT

C

navicular bursa

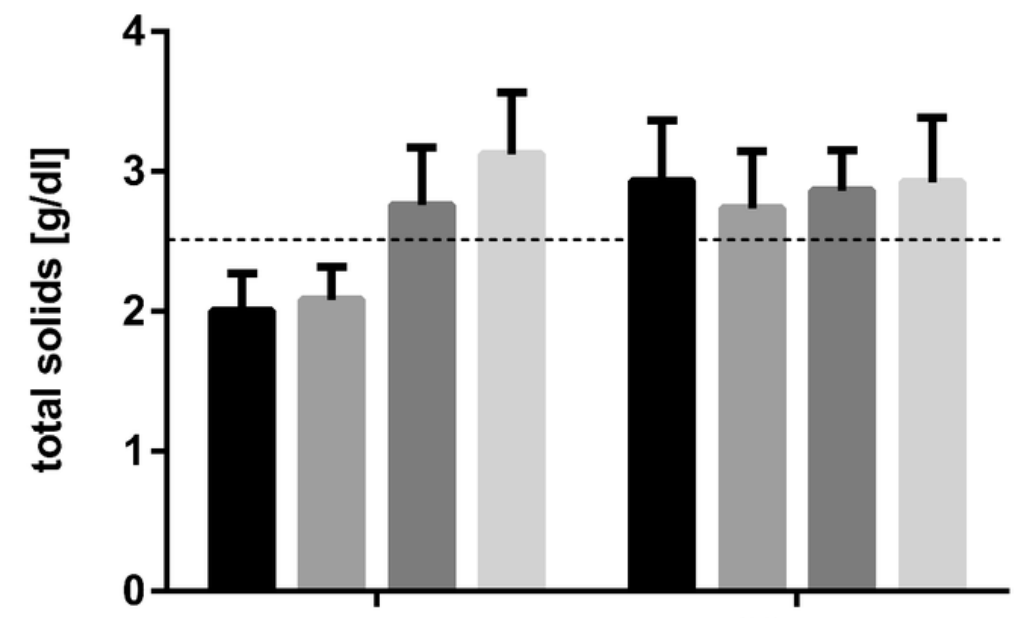

LDC

LDT

HDC

HDT

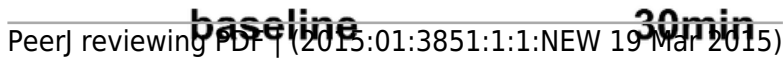


2

Bar graphs illustrating synovial fluid total nucleated cell counts after IVRLP with tiludronate or saline

Figure 2: Synovial fluid total nucleated cell counts over time after IVRLP with $0.5 \mathrm{mg}$ (LDT) or $50 \mathrm{mg}$ (HDT) tiludronate diluted in $50 \mathrm{ml}$ saline in one randomly assigned forelimb or with 50 $\mathrm{ml}$ saline in the contralateral forelimb as control for the low dose (LDC) or as control for the high dose of tiludronate (HDC). Synovial fluid was sampled from the metacarpophalangeal joint (A), the coffin joint (B) and the navicular bursa (C). The dotted line represents the upper limit of the normal reference interval (Mahaffey, 2002). An asterisk indicates significant difference $(P<0.05)$ from baseline measurement. Error bars represent SEM. 


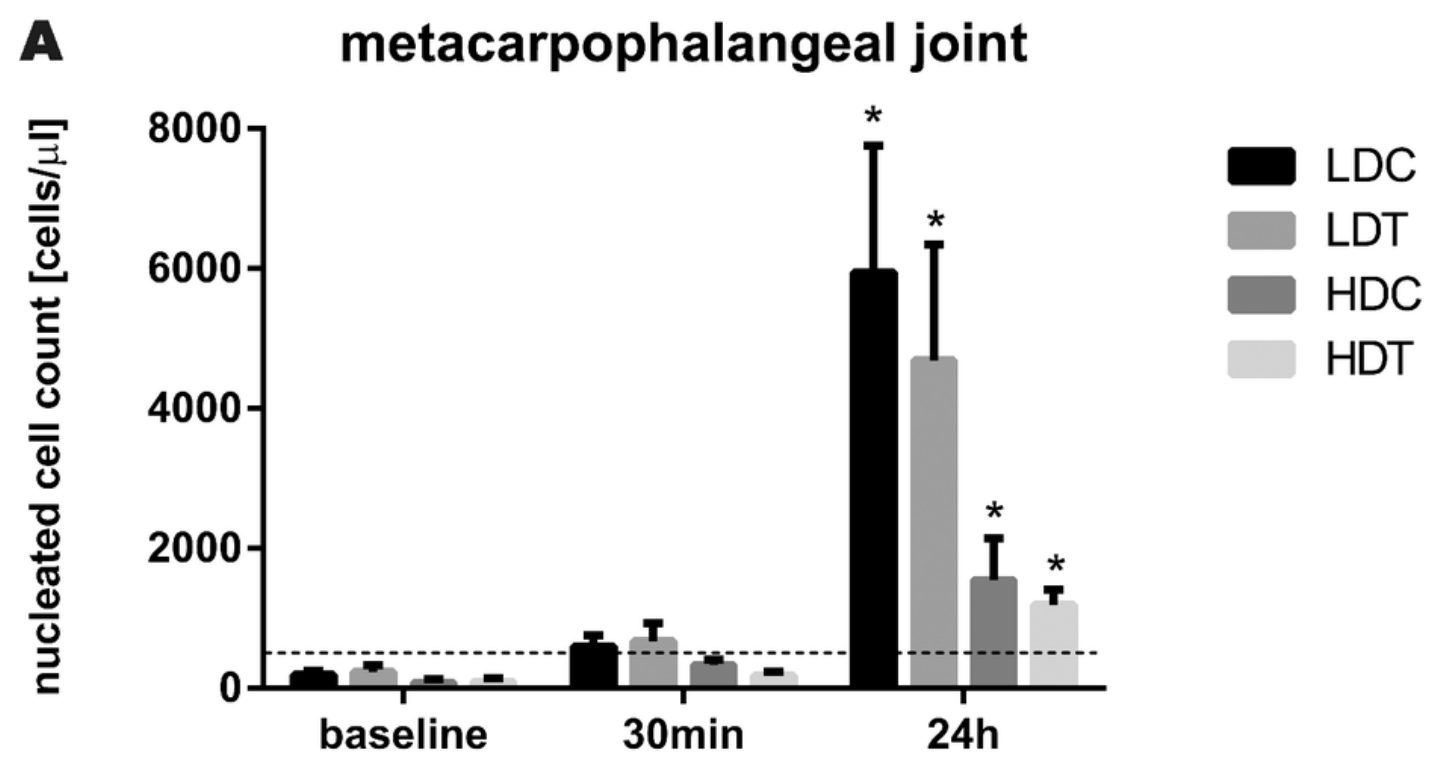

B proximal interphalangeal joint

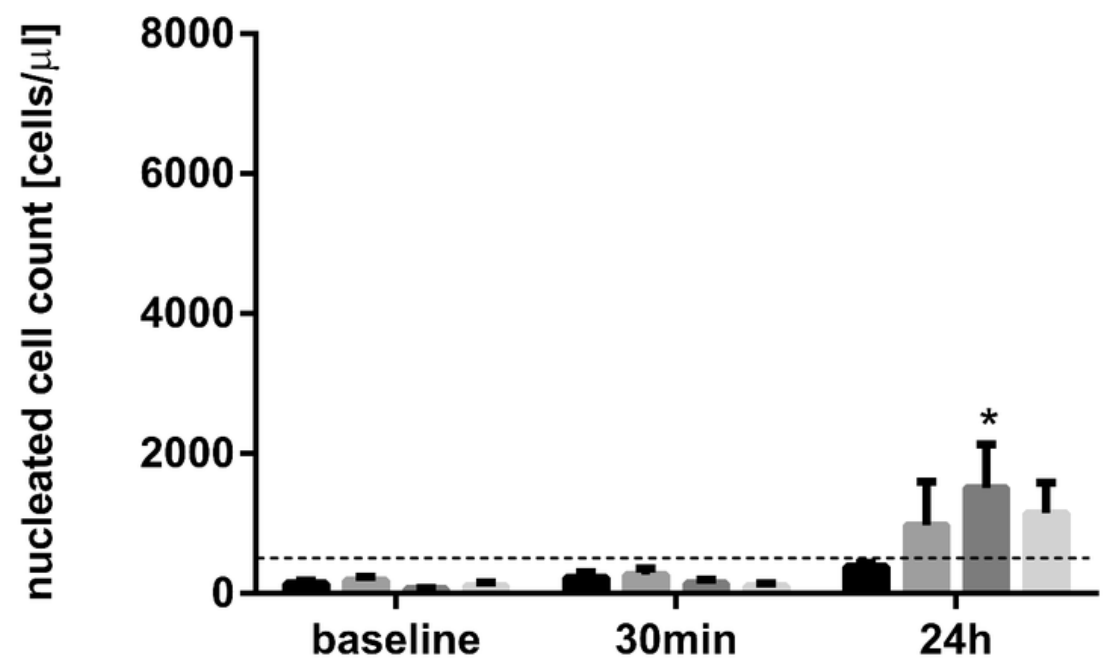

C navicular bursa

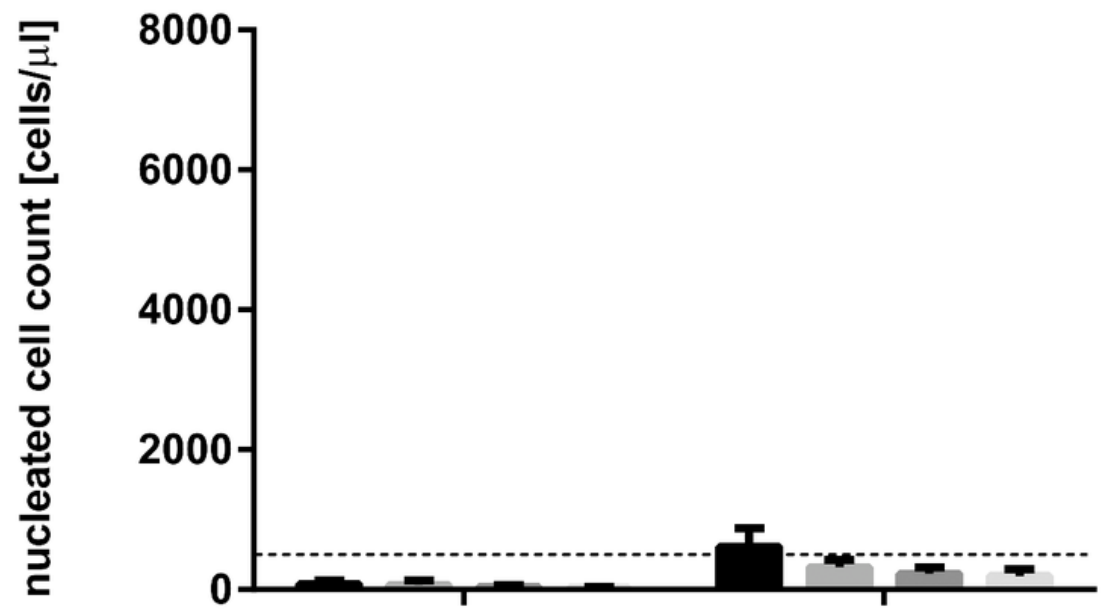

$\square$ LDC

LDT

HDC HDT 